\title{
Language learning and teaching
}

THEORY AND PRINCIPLES

See also abstracts 78-23, $-92,-126$, $-131$

78-58 Bertrand, Yves. Remarques sur les objectifs de l'enseignement des langues. [The aims of language teaching.] Langues Modernes (Paris), 71, 3 (1977), 215-30.

The officially stated objectives of modern-language teaching in French secondary schools are examined: (1) the practical aim of communication (somewhat vaguely defined) in the foreign language; (2) the cultural objective; (3) an educational objective (training the mind); (4) a political aim - the idea that speaking foreign languages leads to international understanding. In the conditions actually prevailing in schools these aims fall far short of achievement and are to some extent in conflict with one another. Teachers themselves are not in agreement over the aims to be achieved; nor is there full accord between teachers and the authorities - and the aspirations and expectations of students differ from those of their teachers. There exists a fundamental contradiction between professed aims and the methods used to pursue them; means should be better adapted to ends. Some suggestions are made for improving the situation.

78-59 Davies, Norman F. Receptive versus productive skills in foreignlanguage learning. Modern Language Journal (St Louis, Mo), 60, 8 (1976), 440-3.

Communication between people of different nationalities can often be more satisfactory when each speaker uses his own language, instead of trying to speak another's. Yet educational systems normally assume that active communicative ability, rather than receptive skills, are the only objective. Instead, it is proposed that fewer languages should be studied for productive skills, and more for receptive - perhaps, in addition to the native language, one at the productive level plus two at the level of aural comprehension. At higher levels, reading courses should be available in languages closely related to those already studied. There is a need for courses and materials designed to train the receptive skills. [Advantages of the proposed scheme are outlined.]

78-60 Davies, Norman $F$. The changing role of the university language department. System (Linköping, Sweden), 5, 1 (1977), 38-45.

Factors which affect the tertiary sector of education with regard to the teaching of modern languages are: (1) declining interest among school-leavers; (2) 
growing demand from adults; (3) demand for specialised courses. The three main organisational choices to cater for these new groups of learners are new institutions, new sections within existing institutions, or that existing institutions widen their field. The latter alternative is exemplified by experience in Sweden at the University of Linköping, where about 75 per cent of the English Department's annual intake consists of part-time students. The courses offered fall into four categories: (a) extra-mural courses, $(b)$ decentralised courses (elsewhere in the region), $(c)$ distance teaching, and $(d)$ languages for professional use. [Advantages to be gained if university language departments widen their field in these ways.]

78-61 Doe, Bob. Most language teaching a waste of time-HMIs. Times Educational Supplement (London), 3224 (18 March 1977), 3.

The third report in the HMI series Matters for discussion indicates that much modern-language teaching is a cause for grave concern. It recommends that the top third of the ability range should be singled out as soon as possible to take language courses up to the age of 16 . The rest could be given less demanding language courses. Too many pupils gave up language study prematurely, by the age of 14 . The most able pupils were not stretched enough: teaching was pedestrian and tied to the examination programme. Most schools had sufficient equipment but one in eight was short of textbooks. Where pupils had started French in primary schools, they usually had to begin again in the secondary school. Languages other than French were rarely, and no better, taught.

78-62 Gutschow, Harald. Zum Problem der theoretischen Begründung der Didaktik des Fremdsprachenunterrichts. [The problem of a theoretical foundation for the didactics of foreign-language teaching.] Englisch (Berlin), 12, 1 (1977), 1-6.

A critical evaluation of the latest attempts at a theoretical foundation for the didactics of foreign-language teaching. (1) Applied linguistics promises to make possible teaching guided by linguistic theories. Transformational grammar is of particular importance, since it favours the traditional German esteem for grammar and conscious learning. From a didactic point of view it can be criticised in that the problem of communication is disregarded, that it is misguided to teach pure grammar and that the problem of conveying knowledge remains undiscussed. (2) The latter are the starting points for the psychology of learning which distinguishes between the pupil's manipulative and creative skills and puts forward the methodical principle of assimilation-manipulation - free creative activity. (3) Another attempt at giving didactics a theoretical foundation is made in so-called pragmatism, which places communicative competence in the foreground and considers language as a series of speech-acts. 
This approach, however, considers language only as a means to pursue one's own interests.

All these theories have neglected the routine of teaching; moreover, they have often caused a feeling of insecurity in teachers. A sensible theory of didactics must take into account the practical implications of teaching and above all the pupil's capacity and the conditions under which he is learning.

78-63 Lee, W. R. For and against an early start. Foreign Language Annals (New York), 10, 3 (1977), 263-70.

The problem of when to begin foreign-language teaching necessarily involves questions concerning the content of a basic education. Early introduction of foreign-language teaching has often rested on the belief that younger children are especially good language learners, as in some respects they probably are. However, even if they were not, this would not be a valid reason for beginning later. [Detailed criticism is made of the conclusions of Primary French in the Balance.] An early start may be favoured because of the effect on the children's minds at the time of learning. Improvements in teaching and the development of a middle school may help to solve some of the problems of transition to the more advanced stages. Experiment with the timetable and with intensive teaching is also desirable, at primary as at other levels.

78-64 Pons-Ridler, Suzanne. Introduction précoce de la langue seconde. Expérience suisse: exemple à suivre? [Early introduction of the second language. Is the Swiss experiment an example worth follow. ing?] Canadian Modern Language Review (Toronto), 33, 4 (1977), 453-8.

Swiss trials on the early introduction of a second language started in 1969. In 1974 they involved 13,500 pupils. The commission's recommendations were as follows: children should begin at or before age 10 ; should study for at least two hours a week; the class teacher should teach the target language; teachers must be specially trained and qualified; the commission's instructions must be followed. [Discussions and observations.] Training of teachers is the most important factor for success. A second language is no longer seen as a luxury.

PSYCHOLOGY OF LEARNING See also abstracts 78-97, -109, -123

78-65 Blaubergs, Maija S. Encoding self-embedded sentences. Language and Speech (Hampton Hill, Mddx), 19, 1 (1976), 1-8.

Are encoding and decoding mirror-image processes? Previous studies show that semantically supported self-embedded sentences are easier to decode than 
semantically neutral sentences. A procedure for testing encoding is developed. The hypothesis that semantically supported self-embedded sentences are not easier to encode than semantically neutral sentences is supported. An analysis of the errors made indicates that although errors increase with increasing sentence complexity, subjects can produce the correct orderings of subjects and predicates in sentences with up to five degrees of self-embedding. It is concluded that the scarcity of complex self-embedded sentences is not based primarily on memory limitations in the encoding of sentences, but more likely on the memory requirements in decoding.

\section{$78-66$}

Fathman, Ann K. Variables affecting the successful learning of English as a second language. TESOL Quarterly (Washington, DC), 10, 4 (1976), 433-42.

Success in learning a second language may be influenced by many variables, including differences in environmental surroundings and individual characteristics of the learner. There have been few studies which systematically examine the influence of these variables. This paper examines the effect which certain environmental variables have upon learning to speak English as a second language.

Approximately 500 elementary and high-school students enrolled in Englishas-a-second-language classes in public schools were administered oral production tests at the beginning and end of the school year. These tests, an oral interview or the Second Language Oral Production English (SLOPE) Test, were given to students in different schools who were in various types of ESL programmes. The pre- and post-test scores were used to assess progress made during the school year. The scores were then examined to describe the influence that multiple variables had upon progress in English oral production. The variables examined included such differences as time in ESL class, size of class, method of teaching and number of foreign students in the school. It was found that all groups of students made significant progress in speaking English during the school year, but that those making most marked improvement were in school settings where the use of English was encouraged and necessary for effective communication.

78-67 Glanzer, Murray. Intonation grouping and related words in free recall. Journal of Verbal Learning and Verbal Behavior (New York), 15, 1 (1976), 85-92.

Two studies were carried out demonstrating the interaction of intonation grouping and meaning relations between words in free recall. When the intonation grouping is in phase with the word relations, recall is facilitated. When it is out of phase, recall is lowered. This is an effect on long-term store. A 
separate effect of intonation grouping on short-term store is also replicated. The relation of these effects to the processing of language is considered.

78-68 Holyoak, Keith J. and Walker, Janet $H$. Subjective magnitude information in semantic orderings. Journal of Verbal Learning and Verbal Behavior (New York), 15, 1 (1976), 287-99.

Subjects compared the magnitudes of pairs of concepts from the semantic orderings of time, quality and temperature, choosing either the concept that was longer/better/warmer or the concept that was shorter/worse/colder. Decision time depended on two factors: (1) decision time decreased as the subjective difference between the magnitudes of the two concepts being compared increased; (2) the decision was made more quickly when the form of the comparative in the question was congruent with the scale position of the terms being compared. For example, it was easier to choose the longer term of the pair decade-century, and the shorter term of the pair second-minute. The results demonstrate that the semantic representations of ordered terms contain subjective magnitude information.

78-69 Katz, Albert N. and Denny, J. Peter. Memory-load and concreteness in the order of dominance effect for verbal concepts. Journal of Verbal Learning and Verbal Behavior (New York), 16, 1 (1977), 13-30.

Previous research has shown that concrete concepts are more readily attained than abstract concepts. This order of dominance phenomenon has been well established for figural concepts and has been suggested for verbal concepts. In the present study the effect was confirmed for verbal materials, even when the instances and concepts were equivalent with respect to instance frequency, meaningfulness and conjoint frequency. In addition, the dominance effect was especially marked under high memory-load conditions, and for subjects who had difficulty in remembering previously presented instances. These findings were interpreted to support a new theory of the order of dominance effect for verbal materials; concrete concepts are in part more readily attained because, under the high memory load for previous instances which was obtained in earlier experiments, concrete word instances are more readily available from memory.

78-70 Kunzendorf, Robert G. Selected features of word meaning. Journal of Verbal Learning and Verbal Behavior (New York), 15, 6 (1976), $633-40$.

Under certain experimental conditions, the fact that a given word (e.g. lilac) belongs to a relatively large category (plants) was affirmed more quickly than 
the fact that it belongs to a relatively small category (flowers). This result, in conjunction with other results obtained in the current experiment, tends to contradict the predictions of previous theories of word meaning and lends support to a feature selection theory derived from Garner's (1974) critical realism position.

78-71 Manelis, Leon and Yekovich, Frank R. Repetitions of propositional arguments in sentences. Journal of Verbal Learning and Verbal Behavior (New York), 15 (1976), 301-12.

This study investigated a characteristic of the propositions that underlie sentences. For some of the sentences that were tested, the same concepts occurred repeatedly across the underlying propositions, and for other sentences, concepts were seldom repeated. Repetitions were shown to facilitate processing of the sentences in three experiments. Experiment I demonstrated an effect of repetitions on the time subjects took to read with comprehension. Experiment II demonstrated an effect on immediate recall. Experiment III demonstrated a facilitating effect on immediate recall, even though the sentences containing repetitions were longer and more complicated than those that did not. These results were explained by two processes: integrating information during comprehension and retrieving propositions from memory.

78-72 Matsuda, Noriyuki and Robbins, Donald. Prototype abstraction and distinctive feature learning: an application to learning Chinese characters. Journal of Educational Psychology (Washington, DC), 69, 1 (1977), 15-23.

Chinese characters with related meanings often have a common symbol included among their components. In an exemplar-prototype and distinctive feature classification system, the multiple-component characters (the exemplars) can be said to have a common component (the prototype) distinctive to the shared concept. Using recognition tests with new and old exemplars and prototypes, the traditional language-learning technique of paired-associate training with exemplars of Chinese characters and specific English translations led to the poorest performance of the three methods tested. Learning either the English concept of Chinese exemplars (exemplar-category training) or the English concept for only the distinctive feature (prototype training) produced greatly superior performance. Instructions regarding the nature of Chinese characters had no effect on performance. 
78-73 Neufeld, Gerald G. Language-learning ability in adults: a study on the acquisition of prosodic and articulatory features. Working Papers on Bilingualism (Toronto), 12 (1977), 45-60.

This paper reports on a study in which 20 young adults were tested for their ability accurately to reproduce the articulatory and prosodic features of three non-Indo-European languages in which they had received instruction. The first of two basic goals of this research was to test, at the purely phonetic level, the 'critical period for language learning' hypothesis (Lenneberg, 1967). The second problem was to see if students could acquire the linguistic features associated with language accent with no reference to grammar or lexical meaning. Both questions are considered, with special attention to the concrete results of the study and to their implications. The final section of the paper includes a discussion of the acoustic image imprinting theory, which is the basis for the method used to teach phonetic material in this experiment.

\section{ERROR ANALYSIS See also abstract 78-130}

78-74 Bautier-Castaing, Elisabeth. Modèles syntaxiques et stratégies d'apprentissage. [Syntactic models and learning strategies.] Français dans le Monde (Paris), 129 (1977), 54-9.

The proliferation of models of language description has produced an attempt to develop teaching methods based on linguistic models. Unfortunately these models, however theoretically satisfying, are of little pedagogical value in producing communicative competence. It is desirable to shift attention from linguistic models to strategies of language learning, so bringing the learner into the centre of method development as the informant on learning strategies. The concept of an innate language-learning capacity operating by successive approximations to a target syntax leads to the postulation of an 'intermediate competence' (compétence intermédiaire).

The source of error is therefore not solely interference from the native language, but also a function of the stage of learning the target language. This means that native-speaking children and second-language learners will make similar errors. This hypothesis was tested on three groups of children: Frenchspeaking four-year-olds; French-speaking eight-year-olds (to test the influence of school), and children of various languages, aged from four to eight years, with about eight months' exposure to French. This last age-group was chosen to obviate conscious, analytical knowledge of their native languages. [Test results, with descriptions of errors and deficiencies among second-language learners in terms of the logical complexity of the target structures.] Results confirmed the hypothesis of 'innate capacity' and consequent similarity of 
learning strategies. A further consideration is the difficulty of assessing discourse phenomena through lack of a precise description.

78-75 Ho-Peng, Lim. Errors and error analysis in TESL: the Malaysian experience. RELC Journal (Singapore), 7, 2 (1976), 23-9.

Error analysis is one way to help teachers predict what errors their students are likely to make and thus help them to avoid them. General types of recurrent errors which can be observed in a Malaysian ESL learner's acquisition are listed and discussed, including interlanguage errors, intralingual and developmental errors, and over-generalisation errors. [Examples]. [References.]

78-76 Porquier, Rémy. L'analyse des erreurs: problèmes et perspectives. [Error analysis: problems and possibilities.] Études de Linguistique Appliquée (Paris), 25 (1977), 23-43.

This is a review of current aims, procedures and taxonomies in error analysis. Error is seen as an essential component in the learning process. Future developments are likely to emphasise the role of the learner as informant; the theoretical basis will shift towards psycholinguistics and functional linguistics. Taxonomies of error will account for conceptualisation, language register, context of utterance and systematic versus casual mistakes. Investigations will make longitudinal observations, and may use elicitation procedures. Errors in comprehension have been little studied and present a challenge.

78-77 Rattunde, Eckhard. Transfer-Interferenz. Probleme der Begriffsdefinition bei der Fehleranalyse. [Transfer - interference? Problems of concept-definition in the analysis of mistakes.] Die Neueren Sprachen (Frankfurt am Main), 26, 1 (1977), 4-14.

The lack of uniformity in the use of the terms 'transfer' and 'interference', which serve to determine causes of mistakes, is exhibited. After a critical discussion of the various terminologies a pragmatic means of conceptual differentiation is offered in the field of foreign-language learning. Inference is defined as a generic concept; transfer means the forming of correct analogies between the native and the foreign language as well as between structures of the foreign language itself. Interference is the forming of incorrect analogies. This terminology avoids an overlapping of concepts and deliberately disregards the distinction between cognitive and non-cognitive, since in foreign-language teaching it is impossible to know whether a mistake is due to cognitive or habitualised processes. 


\section{TESTING}

78-78 Aitken, Kenneth G. Using cloze procedure as an overall language proficiency test. TESOL Quarterly (Washington, DC), 11, 1 (1977), $59-67$.

The cloze procedure may provide valid, reliable second-language proficiency tests. This paper discusses the construction, administration, scoring and interpretation of cloze tests of overall language proficiency. Other uses of the cloze in ESL are mentioned. Finally an explanation of the cognitive processes in doing cloze tasks is offered.

78-79 Bowen, J. Donald. Current research on an integrative test of English grammar. RELC Journal (Singapore), 7, 2 (1976), 30-7.

A study was made of the correlation of the part and whole scores of three tests: the integrative grammar test (IGT), the American University in Cairo's admissions battery, and the Egyptian secondary-school leaving examination. [Description of the IGT, detailed comparison with the other tests.] The IGT test is built on the assumption of the redundancy principle. The distortion or obscuring is accomplished not by cutting out or masking over data, but by testing the ability of subjects to reconstruct and identify the normal forms of the meanings and constructions of informal, conversational English. If the non-natives develop expertise for these identifications, their mastery of English grammar should be commensurately improved. The IGT identifies and clearly separates native and non-native speakers of English, reliably measures the competence of non-natives, and correlates well with a normed standard test of English proficiency, the Michigan test, and especially well with the sub-test in grammar. [The IGT is also described in abstract 77-49.]

78-80 Boyle, Thomas A. and others. Computer-mediated testing: a branched programme achievement test. Modern Language Journal ( $\mathrm{St}$ Louis, Mo), 60, 8 (1976), 428-40.

An inexpensive application of the computer in secondary education, analysis of responses to questions about basic concepts during unit-by-unit instruction, is described, together with a Branched Programme Achievement Test (BPAT) suitable for computer analysis. The combination of computer mediation and programmed testing is shown to be an efficient way of helping teacher and student to identify inadequate learning. In terms of complexity and cost, computer analysis of programmed tests comes half-way between computerassisted and computer-managed instruction. [Tables of results and sample test (in beginners' French).] [References.] 
78-81 De Jong, W. N. On validating a pronunciation test. English Language Teaching Journal (London), 31, 3 (1977), 233-9.

A phoneme elicitation test was developed to test first-year students in the English Department of a Dutch teacher training institute. Two types of elicitation were tried out; a picture-stimulus test and a quiz. It was found with the quiz that questions had to be worded extremely carefully [examples] and that administration was too complex. With the picture-stimulus test, difficulties arose with ambiguous drawings, and even supposedly common words seemed to be unknown to the students. The vocabulary should be familiar to all the students, so is best selected from the textbook or material which they have been using. Knowledge of idioms or of cultural background should not be assumed. Words which are similar in the foreign and native language should be avoided.

78-82 Gaies, Stephen J. and others. Toward the measurement of functional proficiency: contextualisation of the noise test. TESOL Quarterly (Washington, DC), 11, 1 (1977), 51-7.

In its original form, the noise test is a dictation of fifty discrete English sentences, varying in syntactic complexity, recorded on tape with accompanying background white noise. In terms of both its theoretical rationale and its statistical reliability, the noise test has generally been accepted as a useful instrument for evaluating overall English proficiency. A recent study, however, suggested that while the noise test clearly indicates the non-native proficiency of a subject, 'it exaggerates to some degree the difference between a subject's ability to function in a normal, real-life situation of reduced redundancy and that of a native speaker'. The study also asserted that further judgments about the usefulness of the noise test could be made only after revision of the instrument, with special emphasis on contextualisation.

The present study describes the revision process, which attempted to increase the face validity of the test, primarily used to evaluate the proficiency of EFL/ESL students planning to pursue university degree work. Technical aspects of adding background noise, attempts to control for syntactic comparability among the test items, and preliminary data on the performance of the revised instrument are discussed.

78-83 Goodrich, Hubbard C. Distractor efficiency in foreign-language testing. TESOL Quarterly (Washington, DC), 11, 1 (1977), 69-78.

The purpose of the investigation was to discover the relative rank order of efficiency of eight distractor categories in multiple-choice foreign-language vocabulary tests. The questions postulated were the following: (1) Which 


\section{LANGUAGE LEARNING AND TEACHING}

distractor category has the greatest potency to attract students away from the correct response? (2) Which distractor category has the greatest facility to discriminate or separate students into proficiency levels? (3) What differences are there between populations of the same language but from different geographical areas? The type of test question used was clarified, the types of distractors were defined and the process of selection described, the test design was discussed, and the resulting data tabulated and intepreted.

A definite hierarchy of preference was found, also differences and agreements in the effectiveness of the distractor types. Greater differences existed for these populations of contrasting English proficiency. Few differences existed for the populations of similar proficiency. No differences existed for the populations of similar proficiency but dissimilar location.

78-84 Hollomon, John W. A practical approach to assessing bilingualism in young Mexican-American children. TESOL Quarterly (Washington, DC), 10, 4 (1976), 389-401.

This article presents a practical approach to assessing bilingualism in children entering school. It includes the general aim of bilingual assessment, and an overall approach, which includes a method of selecting subjects, the use of a sociolinguistic survey, and tests for measuring bilingual communicative competence. It also suggests variables to be included in the analysis of data, as well as some limitations of the tests discussed.

78-85 James, A. J. and others. What Queen's English do universities accept? Times Higher Education Supplement (London), 289 (6 May 1977), 22.

Universities in Britain were surveyed to find out which English language examinations they recognised as most suitable for overseas students who mainly wished to read sciences at a British university [summary and table of replies]. The majority of universities consulted required either the Cambridge Proficiency examination or the JMB test in English (Overseas) as equivalence to ' $O$ '-level English, but the former requires too long a preparation time, and the latter is widely regarded as unsuitable for students who do not have English as their first language. Universities are not consistent in their requirements, and some prefer other tests such as TOEFL or their own internal tests. It is felt that some standardised policy should be evolved. Examinations for specific purposes may be more useful: the University of Cambridge Local Examinations Syndicate hopes to introduce a new test aimed at the special needs of overseas students in such areas as business studies and science. 
78-86 Nevo, Barukh and others. 'The rich get richer and the poor get poorer': a quantitative evaluation of the outcomes of a programme for teaching English as a foreign language. System (Linköping, Sweden), 5, 1 (1977), 33-7.

This study is an attempt to evaluate the effectiveness of a standard one-year advanced English course. Three hundred and twenty-two freshmen from Haifa University were tested with the same English comprehension test twice: before and after the course. An improvement score defined by the difference between the two administrations of the test was computed for each student. In the statistical analysis, the sample was stratified into four groups according to the student's first (before) score, labelled: low, middle-low, middle-high, and high. Results indicated that improvement was significant for each of the three upper groups while the low group showed no improvement at all. When comparing the improvement mean scores of the four groups, a general trend was found: the higher the initial level of a student is, the larger his improvement score will be.

78-87 Rabinovitch, F. M and Rozenkrantz, M. В. О составлении тестов для контрола понимания в процессе чтения. [On the construction of tests for monitoring reading comprehension.] Pycский язык за рубежом (Mоscow), 3 (1977), 34-40.

In the first part of the paper, the authors list various types of reading comprehension test (e.g. recognition, alternative response, multiple-choice, rearrangement). Thereafter follows a discussion of the multiple-choice test in relation to the key question of the construction of correct alternatives and distractors. Finally, suggestions are made for the construction of multiple-choice tests in relation to three types of text: literary, popular-scientific, and sociopolitical. Different types of alternatives and distractors are discussed for each type of text [details and examples].

\section{CURRICULUM PLANNING}

78-88 Wigram, M. R. A national plan for languages? Modern Languages (London), 58, 1 (1977), 1-7.

Three questions are discussed. (1) Why do we need a national plan? Planning is needed, especially in the secondary sector, because without it such issues as the reorganisation of teacher training become impossible. The right of the individual school to decide for itself on the curriculum may need to be sacrificed to some degree to ensure continuity of teaching. (2) Is it possible to have a national plan? Responsibility for implementing such a plan should be assigned 


\section{LANGUAGE LEARNING AND TEACHING}

to the LEAs, but the Secretary of State should provide them with effective leadership in the field of curriculum and examinations. A 'Council for Curriculum and Examinations', consisting of representatives of DES, LEAs, teachers, parents and employers, could recommend guidelines to the Secretary of State. The guidelines would be concerned only with broad strands of curriculum policy where coordination between schools was important; the schools would still be free to arrange programmes of work with the overall framework. (3) What should the national plan contain? Areas where guidelines could help schools and topics which the Council for the Curriculum might study are outlined.

\section{COURSE DESIGN See also abstract 78-93}

78-89 Vogel, Klaus. Communicative competence as a performance objective and its realisation in foreign-language teaching. System (Lund, Sweden), 5, 1 (1977), 46-57.

Despite the current emphasis on communicative ability, traditional teaching methods are retained which violate the principle. Three main reasons for this are outlined: (1) analysis of the 'multi-functionalism' of language has been neglected; (2) theoretical models of grammar fail to construct rules governing the use of language in communicative situations, and (3) a rigid enumeration of the various factors in such situations is needed before the dynamic relations of these situational elements can be described. [Fundamental factors which make up communication, such as speaker, listener, form and content of message, are listed.] Jacobson's model is used as a basis for developing a proposal for the design of foreign-language courses based on the communicative interpretation of language functions. [Areas of activity and corresponding learning objectives are suggested, and didactic advantages outlined.]

\section{TEACHER TRAINING}

78-90 Choseed, Bernard. An exchange teacher at the Kiev State Pedagogical Institute of Foreign Languages. TESOL Quarterly (Washington, DC), 11, 1 (1977), 87-96.

This report is based on a visit to Kiev in 1974 under the AFS-Soviet language teachers exchange. The Kiev FL Teachers Institute is described in terms of numbers, organisation, activities and level of English proficiency. The programme is followed from entrance qualifications to post-graduation prospects. Specific aspects of Kiev English are listed, and a brief survey is made of overall methodology, some of the textbooks used, and of the physical facilities. An 
attempt is also made to examine the internal structure of both the student body and the faculty, and of their work loads and financial arrangements. Despite ambiguities, incurred in part by the brevity of the exchange term, the experience has proved beneficial to the Kiev Institute and to the Americans involved.

78-91 Palmer, Brian. Can language teaching avoid the rocks ahead? Times Higher Education Supplement (London), 295 (17 June 1977), 11.

The debate on the future of modern-language teaching has focused mainly on primary French and the place for languages in a 'core curriculum', but scant attention has been paid to the problem of providing suitably trained teachers in the next decade. Recent surveys have warned of shortages; many posts are filled by inadequately trained people. By the early 1980s language teaching in schools could be in a disastrous situation. The total intake into the former colleges of education will be reduced to about one third of the 1970 figures as from September 1977 [figures provided]. Colleges asked to comment on their likely future were pessimistic, estimating that in 50 per cent of cases they would cease to offer French courses by 1978 . University departments of education may help to provide a solution. There is a need for publicity designed to counter the impression that there is a surplus of teachers across the board, and for some sort of central intervention to rationalise or regionalise courses.

TEACHING METHODS See also abstracts 78-100, $-102,-112$

78-92 Besse, Henri. Épistémologie grammaticale et exercices grammaticaux. [Forms of grammatical knowledge and grammar exercises.] Études de Linguistique Appliquée (Paris), 25 (1977), 7-21.

A detailed examination of kinds of awareness of grammar (implicit and explicit) is followed by an analysis of assumptions made by designers of drills. The relationship between explicit teaching of grammar and conceptualisation of 'rules' is examined. Students' knowledge is viewed as an evolving awareness. Suggestions are given for encouraging discussions, at intervals during the course, about students' current views of a particular 'rule': each discussion is a kind of stocktaking prior to further exploration of the target language.

78-93 Candelier, Michel. Analyses linguistiques et enseignement des langues étrangères: principes de bon usage illustrés. [Language analysis and foreign-language teaching: principles of sound practice illustrated.] Etudes de Linguistique Appliquée (Paris), 25 (1977), 67-87.

The writers of some pedagogic grammars retain only the terminological paraphernalia of TG; for students, TG abstractions can be more difficult than the 
target language itself. But the teacher/writer can use the insight of sentence structure he has gained to work out teaching progressions, exercises, and the content of grammatical explanations. TG may clarify his options but will not prescribe his strategies. [Illustrative analyses examine four complex German sentences which realise one message. Reference is made to Hartung's 1964 analysis for insight.]

78-94 Diegritz, T. and Rosenbusch, H. S. Schülerkommunikation in Gruppenunterricht und Frontalunterricht. Eine vergleichende Studie. [Pupil communication in group work and full class work. A comparative study.] Linguistik und Didaktik (Munich), 8, 29 (1977), $1-28$.

Since human communication is influenced by special circumstances there must be a difference in performance in group work and full class work. A comparative methodological study was therefore carried out in the third form of a primary school in which group work had already been practised once a day for five months. A fixed camera and tape-recorder were used to study the full class and a group at work. A story was read in sections by the teacher and the class was then divided into groups to try to decide on a possible conclusion to the story. The final section was then presented by the teacher to the full class. It was found in the group work that although no conclusion was agreed upon all members frequently addressed the group, a clear leader emerged, the group took on a certain coherence and no outsider was in evidence. The speed of communication was faster although less words were actually used. The group work yielded a greater variety of language, the presentation of personal opinions predominated, and personal and emotional reactions were over-represented. Interruptions and non-verbal communication were more frequent. The group had a more private, intimate character than the full class situation, in which all threads of conversation went through the teacher, who was in a clearly superior position of authority. All class members spoke much less than in the group, nearly half not contributing at all. There was no direct interaction between the pupils, rather reactions to the teacher's reaction to the last pupil's contribution. Content played a greater part since the teacher was the only one who had the aim of the lesson fully in mind. An analytical evaluation was made, dividing the data into three different sections: Konstativa, Positionale and Evaluativa, each with subheadings. 
78-95 Moirand, Sophie. Analyse de textes écrits et apprentissage 'grammatical'. [Analysis of written texts and 'grammatical' teaching.] Études de Linguistique Appliquée (Paris), 25 (1977), 101-25.

Experience with the use of written documents for the teaching of grammar [references] shows that it is necessary to consider the function of a text in the light of the communicative intentions of the author. Even if the object is grammar teaching, it is necessary to penetrate beyond the syntax, since this is integrated with the written or oral discourse situation. In this approach a text is seen as translating the communicative intentions of the author to an audience by means of a message in which the syntax acts as an ordering device depending on the linguistic code and sociolinguistic norms. Two consequences follow: that grammatical items are not considered in isolation but as part of the dynamic of the text, and that a preparatory analysis (pré-pédagogique) is necessary so that the learners can apprehend the discourse situation in which the grammatical forms operate. [Examples of preparatory analyses of four contrasted texts.]

Bearing in mind that the presentation in class by no means necessarily follows the sequence of the preparatory analysis, a scheme of such an analysis (sociolinguistic, linguistic, logico-syntactic) is elaborated and explained. Three examples are given of the use of texts following this approach, and the effects on the learners examined. Consideration has to be given to the activation of use of discourse markers (articulateurs) This approach sets the grammar in context and makes it come alive for second-language learners.

78-96 Nation, I. S. P. Creating and adapting language-teaching techniques. RELC Journal (Singapore), 7, 2 (1976), 1-15.

Eight classes of components of language-teaching techniques are described: (1) language material, (2) stimulus, (3) stimulus/response relationship, (4) response, (5) work arrangement, (6) group size, (7) presenting the stimulus, and (8) guiding the response. [Chart]. The teacher can use the chart to make up new techniques to give his students useful practice and add variety.

78-97 Walmsley, John Brian. Motivationsarten und Fremdsprachenunterricht. [Types of motivation and foreign-language teaching.] Neusprachliche Mitteilungen (Berlin), 30, 2 (1977), 65-76.

From the teacher's point of view motivation can be divided into three different categories: (1) achievement-orientated motivation in which standards are defined by the norms of society; (2) affiliation and dominance, i.e. inborn inclinations which are nevertheless influenced from the beginning of childhood by identification, projection and imitation processes; (3) intrinsic motivation, 
i.e. inborn disposition to activity and risk. [Explanation of how these types of motivation relate to the teaching of foreign languages in particular.] In order to create a positive attitude towards learning the teacher must acquire an insight into the pupil's past experiences in learning, his self-assessment and social background. Motivation can be improved by learning in small groups. Intrinsic motivation is drawn upon when the teacher establishes a connection between the foreign language and the child's own world. The child's long-term interests in collecting, observing and listing should be made to serve curricular aims. Short-term interests, such as important events in the target country, can also be utilised.

All this demands a reshaping of textbooks, which so far have over-emphasised the importance of grammar, and better teacher training to enable the teacher to make spontaneous use of new material. More advanced pupils can be made aware of the potential value of a second language as a means of further education.

78-98 Zampogna, Joseph and others. Relationships between learning styles and learning environments in selected secondary modernlanguage classes. Modern Language Journal (St Louis, Mo), 60, 8 (1976), 443-7.

A study was carried out to discover the relationship between student learning styles and a traditionally structured environment or an individualised one in which a variety of teaching methods were used. The aim was to find out which environment students preferred, and whether there is a relationship between the student's concept level (as measured by Hunt's Conceptual Level Paragraph Completion Instrument) and their preference or need for a particular learning environment. [Sample and procedure; results]. All students tested experienced both types of environment for one semester. In the individualised environment they experienced various group-building techniques, mastery testing, a variety of activities and materials including self-instructional programmes, and worked in small groups or alone. In the traditional environment, the teachers structured all activities and taught the class as a whole. When indicating their preferences, students who preferred an individualised environment stated that they liked the ability to learn at different rates and the mastery testing. Students who chose the traditional environment preferred a high degree of structure and pressure, and direct teacher control. Students with high concept-level scores preferred an individualised environment, while those with low scores preferred or needed a traditional environment. 


\section{BILINGUAL TEACHING See also abstract 78-108}

78-99 Bruck, Margaret and others. Cognitive consequences of bilingual schooling: the St Lambert Project through grade six. Linguistics (The Hague), 187 (1977), 13-33.

The cognitive, linguistic and academic skills of two groups of children following an innovative bilingual education programme were examined. These fifth and sixth grade anglophone children, who are being educated in French, are compared to groups of English and French students who are educated in their native language. The results indicate that the experimental children are similar to their English controls in terms of academic linguistic and cognitive skills. In terms of French skills, they function extremely well in their second language although they do not possess native-like proficiency.

78-100 Chaudron, Craig. Teachers' priorities in correcting learners' errors in French immersion classes. Working Papers on Bilingualism (Toronto), 12 (1977), 21-44.

Observation and analysis of classroom interaction is used in a pilot study of grade 8 and 9 French immersion programmes to evaluate the relative importance placed by teachers on the different oral behaviour of students. The frequencies of teachers' corrections for different kinds of students' errors (in L2 skills, subject-matter knowledge, and classroom interaction) are seen to correspond in definite ways to the teachers' stated priorities. The learning of lesson content (in mathematics, science, history, geography and French) is not subordinated to $\mathrm{L} 2$ acquisition.

78-101 Genesee, F. and others. An experimental French immersion programme at the secondary-school level, 1969 to 1974. Canadian Modern Language Review (Toronto), 33, 3 (1977), 318-32.

Until recently, most bilingual or immersion programmes started in kindergarten and continued throughout elementary school. This paper discusses a French immersion programme at the secondary-school level, beginning in grade seven (the first year of secondary school in Quebec) and proceeds to grade eleven (the final year). Approximately 85 per cent of course instruction is given via French, the remainder consisting of an English language arts course. The emphasis is on French as a language of communication. [Research studies on development of language skills and students' attitudes are described.] Results to date are favourable; the programme provides an effective alternative to traditional FSL courses. [References.] 
78-102 Legarreta, Dorothy. Language choice in bilingual classrooms. TESOL Quarterly (Washington, DC), 11, 1 (1977), 9-16.

This article discusses language choices in Spanish bilingual classrooms, based on observations in five kindergartens. The stated objectives for language choice, i.e. 50 per cent Spanish and 50 per cent English, are compared with actual percentages of Spanish and English used by the aduits and children. The amount of teacher talk was also compared to pupil talk, including both free pupil responses and choral responses. Functions of teacher language, such as warming or accepting, directing and correcting children, were also examined in terms of percentages of Spanish and English chosen, Two models were observed, the 'concurrent translation' and 'alternate days'. In the concurrent translation model, it was found that: (1) English is used by bilingual teachers over 70 per cent of total class time; (2) that Spanish-speaking pupils responded with very similar language choices; (3) that teacher talk makes up 80-85 per cent of classroom talk; and (4) that English is again the usual choice for warming or accepting the child's contribution, for directing and for correcting the children. In contrast, the alternate days model generated an equal distribution of Spanish and English by teachers and children overall, with more Spanish used for warming and directing. Again, English was the primary choice for correcting children. It appears that the concurrent translation models does not achieve balanced use (50 per cent Spanish and 50 per cent English) by teachers or pupils.

78-103 Rosier, Paul and Farella, Merilyn. Bilingual education at Rock Point - some early results. TESOL Quarterly (Washington, DC), 10, 4 (1976), 379-88.

A basic assumption of the bilingual programme at Rock Point is that learning to read in the language one speaks will probably result in better reading skills, which will later result in better reading skills in the second language (English), as measured by achievement test scores. The authors believe that critical thinking is developed through language, and that cognitive development is fostered by education in the native language. Nevertheless, good English reading is important, and the authors report significant increases in English achievement test scores of fourth and fifth grade Navajo students who learned to read in Navajo and continued to have content instruction in Navajo while they learned English. The biliterate students at Rock Point scored significantly higher in Total Reading on the Stanford Achievement Test than Navajo students in monolingual BIA schools on the Navajo reservation. The yearly rate of growth of Rock Point students was almost double that that of the BIA sample population. Apparently the effects of initial literacy in Navajo are cumulative. Rock Point's bilingual-biliterate programme demonstrates that instruction in Navajo is both practical and beneficial for Navajo-speaking students. 
78-104 Stern, H. H. The Ottawa-Carleton French Project: issues, conclusions and policy implications. Canadian Modern Language Review (Toronto), 33, 2 (1976), 216-32.

This paper summarises issues and conclusions from two reports by a team at the Ontario Institute for Studies in Education (OISE), based on research from 1973-5. Topics discussed are: the role of research in policy decisions; the choice between core or immersion; programme objectives; cultural and attitudinal education; other educational goals; analysis of the pedagogical issues (amount and distribution of time devoted to French, starting age, and treatment of French - formal or functional); costs and administration. Lastly, the different programmes offered in Ottawa-Carleton are discussed, together with the question of how much the schools can do. [References.]

CLASS METHODS : PRONUNCIATION See also abstracts 78-73, $-81,-122$

78-105 Schmidt, Richard W. Sociolinguistic variation and language transfer in phonology. Working Papers on Bilingualism (Toronto), 12 (1977), 79-95.

This article investigates a specific foreign-language learning problem, the substitution of $/ \mathrm{s}, \mathrm{z} /$ for English $/ \theta, \delta /$ by native speakers of Egyptian Arabic, and concludes that the facts are better explained in terms of language transfer than in terms of inherent difficulty independent of native language. A careful contrastive analysis can make quite precise predictions about the substitution that is made, the learners who make such substitutions and the circumstances under which the substitution is most common. However, it is argued that for the present case a contrastive analysis of the conventional kind, comparing native and target language as static systems, is useless. What is required is a sociolinguistic analysis of the native language, as it is a pattern of sociolinguistic variation which is being transferred to English.

\section{LANGUAGE FOR SPECIAL PURPOSES See also abstracts 78-14,} $-35,-42$

78-106 Havranek, Fleurette. Des entreprises face à la formation en anglais: leurs objectifs et la place de l'anglais de specialité. [Corporations confronted by the need to teach English : their objectives and the place of English for Special Purposes.] IUT Bulletin Pédagogique (Nancy), 25 (1976), 41-51.

An extract from a report on a survey of courses in English at ten French corporations in 1972/3. Courses for (a) the continuing education programme, 
and $(b)$ for special registers. The time estimated for a successful basic course is 350 hours for $a b$ initio students and 600 hours for management. There are clashes between different skills-training objectives. Absolute beginners need a long time for a small return, so tend to be passed over in favour of, say, former IUT students, thus compounding the initial disadvantage. University anglicists should investigate the needs of commerce and industry.

\section{READING See also abstracts 78-87, -119}

78-107 Aravena, B., Luz and Harvey, Anamaria A. La lectura en la enseñanza instrumental de lenguas extranjeras. [Reading in instrumental foreign-language teaching.] Lenguas Modernas (Santiago, Chile), 3 (1976), 31-6.

A discussion of the skills required (including those needing teaching) for efficient reading in a foreign language, summarised in a table. [Bibliography.]

78-108 Bezanson, Keith A. and Hawkes, Nicolas. Bilingual reading skills of primary schoolchildren in Ghana. Working Papers on Bilingualism (Toronto), 11 (1976), 43-73.

The medium of instruction in schools in most African countries is a second language (L2), less attention being focused on the mother tongue or first language (L1) at each successive level of formal schooling. Little attention, however, has been given in curriculum development and research to the building up of the bilingual reading skills of children whose experience in the second language is almost exclusively confined to its school use and whose first language is relatively unavailable to them in its written form. A current theory of second-language learning advances the thesis that reading and writing skills in an L2 are dependent upon the attainment of oral proficiency in that L2. The implication of this thesis is that superior reading and writing performance will be demonstrated in the language medium in which the child has gained the greater oral proficiency. The study reported here examined this implication through an investigation of bilingual reading skills in Ghanaian primary schools. The results show that the nature of the child's bilingual experience, especially in the classroom, may be a far more important determinant of reading ability than the degree of oral proficiency attained, since the children in this study obtained similar mean reading scores in the two languages.

78-109 Francis, Hazel. Children's strategies in learning to read. British Journal of Educational Psychology (London), 47, 2 (1977), 117-25.

Sentences taken from a particular first reader in a well-known school reading scheme, together with variants of these sentences, were read by a sample of 
5-year-old children whose reading skills enabled them to attempt the task. Twenty-four children, 12 of each sex, were selected from each of two very different schools using the reading scheme. The results of planned comparisons between error scores in different forms of the sentences, together with analysis of types of error, showed a strong tendency to revert to familiar sentences in the face of novel versions. There were also signs of early steps in perceiving the letter/word coding of written language. Knowledge of spoken language and of the elements of a phonic approach seemed of little relevance at this very early stage of reading. Reading strategies suggested by this study have already been reported with limited samples of children and learning contexts, and this study tends to show their relative independence of both materials and methods of teaching. Implications for an understanding of early reading and for approaches to instruction are discussed.

78-110 Garrod, Simon and Sanford, Anthony. Interpreting anaphoric relations: the integration of semantic information while reading. Journal of Verbal Learming and Verbal Behavior (New York), 16, 1 (1977), 77-90.

To understand fully the pair of sentences $A$ bus came roaring round the comer; The vehicle narrowly missed a pedestrian, the reader has to deduce that the vehicle in question is a bus which came roaring round the corner. In Experiment 1 it is shown that the reading time for the second sentence in such a pair is in part determined by the semantic distance between the two items to be integrated (vehicle and bus in this case). This result suggests that the information from the two sentences is integrated at the time of reading. Experiment 2 replicates the semantic distance effect in a situation where the two sentences are separated in the text. In Experiment 3 and 4 it is shown that the effect can be abolished under conditions where the two items appear in unrelated phrases. On the basis of these results a model of textual comprehension is proposed.

78-111 Kaplan, Stuart J. and Mohrmann, G. P. Reader, text, audience: oral interpretation and cognitive tuning. Quarterly Journal of Speech (Minneapolis, Minn), 63, 1 (1977), 59-65.

It is argued that reading aloud gives both reader and listener an enhanced experience of the literature. Zajonc's theory of cognitive tuning is cited as support for the theory that preparation for reading aloud stimulates initial impressions significantly different from those formed when the literature is experienced in some other way. A study was carried out to determine whether different communication roles in the reading aloud situation would result in different understanding of the literature, and the effect of the anticipated 
audience on the reader's initial impression [method; results]. Senders were found to have more complex initial impressions than receivers particularly when the audience was familiar to them [discussion].

78-112 Maley, Alan. The teaching of reading skills (1). IUT Bulletin Pédagogique (Paris), 25 (1976), 13-31.

Since the written form of a language differs considerably from the spoken, it will need to be taught separately. It is worth teaching properly as, for many students, the only contact with the foreign language, after leaving school or university, will be through reading. Reading is done $(a)$ for information and (b) for pleasure - both types are done silently, therefore reading aloud as a classroom exercise should not be encouraged [discussion].

Assuming that the student is literate in his own language, the difficulties of reading fall into three main categories: (1) linguistic (problems of lexis, structure and idiom); (2) psychological (isolation, motivation), and (3) cognitive (content problems, cultural problems). Skills which need to be developed are previewing, skimming, scanning, sensitivity to context, questioning/anticipation, structuring, summarising, evaluating and flexibility [brief discussion]. [Exercises to develop these skills are suggested, divided into intensive and extensive reading.] [Bibliography.]

COMMUNICATION See also abstracts $78-59,-89,-94$

78-113 Holmes, Janet and Brown, Dorothy, F. Developing sociolinguistic competence in a second language. TESOL Quarterly (Washington, DC), 10, 4 (1976), 423-31.

This paper presents and discusses some exercises designed to help the secondlanguage learner develop both receptive and productive sociolinguistic competence. The exercises stress the notion of appropriate usage and the potential differences between the sociolinguistic norms of the source and target languages; the importance of recognising the social meaning or latent function of utterances; and the desirability of learners making an active contribution to the development of conversations.

WRITING See abstract 78-116 


\section{AUDIO-VISUAL AIDS}

78-114 Gorodilova,G. G. Технические средства в системе интенсификации обучеиия. [Technical aids for making instruction more intensive.] Русский язык за рубежсом (Moscow), 3 (1977), $50-6$.

The conditions and type of instruction must always be considered along with the use of technical aids, otherwise their introduction may not lead to any improvement. Technical aids for teaching mean technical equipment, various modes of communication and the methodology for using them. Such modes - including pictures and charts - have an important role, as second-language learning cannot be the same as first-language learning. Technical aids are fitted into the learning process depending on which of the teacher's functions they can perform. [The possibilities of various aids are discussed.]

\section{TELEVISION See abstract 78-128}

\section{PROGRAMMED LEARNING}

78-115 McEwen, Nelly. Computer-assisted instruction in second-language learning: an Alberta project. Canadian Modern Language Review (Toronto), 33, 3 (1977), 333-43.

The CAI programme called FRAND, begun during 1973, is described. It aims to teach beginners from elementary level to adults to read and write in French, and teaches these skills within the framework of a grammatically generative system which employs a three-skills approach: listening, reading and writing. The content is based on the Français fondamental. [Description of programme; each unit is divided into three phases: presentation, recognition and response. Students must attain 80 per cent proficiency in any part before continuing.] Field testing indicated that the amount of time needed to complete the programme decreased with the increasing age of students, as did variation among students in each group. Feedback was highly positive. [Revisions described.] The programme has potential for use in a regular French course but the scale of implementation is necessarily limited. [Advantages of using the computer.]

78-116 Zydatiß, W. 'Composition' an der Hauptschule - ein Unterrichtsprogramm. [Composition at primary school - a course of programmed learning.] English (Berlin), 11, 4 (1976), 129-36.

An English course intended for children in the eighth class of Berlin Hauptschulen is described. The school-children are to imagine themselves in the 
position of helping English-speaking foreigners in Berlin by means of describing, explaining and giving information, using situational dialogues, role-playing and producing a guide-book. The aim is to encourage guided composition, particularly letter writing, using a limited number of grammatical constructions. [Description, including tests.]

\section{LANGUAGE LABORATORIES}

78-117 Anderson, Ake. How the language laboratory is used in schools. System (Linköping, Sweden), 5, 1 (1977), 19-26.

A report of an investigation, carried out by means of a questionnaire, on the use of language laboratories in Swedish schools, training colleges and folk high schools, which covered technical equipment, degree and type of use, programmes, teachers' own training, attitudes, problems and needs [details]. It was concluded that the two main factors preventing better utilisation of laboratories are lack of suitable programmes and poor training of teachers. [Suggestions are made for remedial measures.]

78-118 Engels, L. K. Software-Probleme mit der Sprachlaborarbeit: Das Sprachlabor. [Software problems with language laboratory work: the language laboratory.] ITL (Louvain), 34 (1976), 45-72.

There is no one method for the language laboratory but it can be of service to several methods. The 'electronic classroom' caters for almost all aspects of teaching, though it is most suited to smaller schools. Universities and larger institutions should consider other combinations for their language centres - the electronic classroom in the centre, with a small round-about with horseshoe-shaped or round tables as well as spherical classrooms; the latter allow more creativity because all the pieces of apparatus are movable. [Diagrams.]

Unconscious cognitive assimilation and conscious assimilation are discussed. A system for realistic learning of foreign languages is proposed, with a comparison between induction and deduction, noting which stages are best approached consciously cognitively and which unconsciously cognitively. The understanding of grammatical concepts and rules is best done by an inductive learning process and is better for a non-intensive learning situation, particularly the initial stages. The quicker deductive approach is better from remedial work. The point is made that the second stage of internalising rules is often not sufficiently taken into account in most methods. The question of achieving spontaneity is then discussed, though all forms of debate, panel discussion and role-playing must be prepared a week ahead both as to ideas and linguistic content. Cassettes can be taken home as individual aids. [Examples of the use 
of conceptual mediators as memory aids, e.g. money: gold/Geld. Examples of reconstruction exercises on the formation of concepts for use at the internalisation level, for university students and 12 year-olds.]

78-119 Rosenblum, William. The language laboratory supplements the classroom recitation. System (Linköping, Sweden), 5, 1 (1977), 1-6.

The lab programme for an intermediate EFL course for Israeli university students is described. The aim is to improve reading comprehension by teaching students how to approach small passages, rather than concentrating on grammar, style and punctuation. Instruction in the classroom and in the lab need to be co-ordinated. The lab programme concentrates on three specific techniques: increasing the eye-span, skimming and listening comprehension [details].

\section{IMMIGRANTS}

78-120 Prager, Peter. Minority languages. Times Educational Supplement (London), 3233 (20 May 1977), 27.

The foreign languages offered to children from non-English-speaking backgrounds (usually French or German) are particularly difficult for them. A questionnaire given in a London secondary school showed that there was an overwhelming desire to study the mother tongue. It is suggested that at least the major languages (such as Punjabi, Gujerati, Hindi, and Greek) could be taught by peripatetic teachers. This would have the advantage of helping to foster the pupils' own cultures, increase their self-respect and facilitate integration into British society. It would also increase the number of foreign-language passes significantly, and would be a way of distributing educational resources to deprived groups. [Table of questionnaire results.]

ENGLISH See also abstracts 78-30, $-60,-66,-75,-78 / 9,-81 / 6,-90$, $-103,-105 / 6,-112 / 13,-116,-119$

78-121 Cembalo, Michel and others. L'acquisition grammaticale dans un cours d'anglais pour débutants. [The place of grammar in an English course for beginners.] Etudes de Linguistique Appliquée (Paris), 25 (1977), 88-100.

The CRAPEL Cours initial d'anglais oral was designed for use with adult learners and takes into account their particular needs, including the need for a theoretical description of the language being learnt. The emphasis throughout 
is on communication and the approach adopted combines elements from both behaviourist and mentalist concepts of language learning. A sharp distinction is made between the language the students need to understand and the language they need to learn and use; both types are presented, and progress, independently of each other. The course was first tried out with a pilot group in 1975/6. Results so far indicate that transfer of knowledge from comprehension to expression does occur and that student progress is facilitated.

78-122 Chen Chung-yu. Pronunciation of English by students from the Chinese stream in Singapore: some salient features. RELC Journal (Singapore), 7, 2 (1976), 54-60.

The English pronunciation of 70 students was studied. A speech habit shared by most of them is the sporadic addition or omission of one or more consonants at the end of a word [examples]. Some areas of difficulty are specified.

78-123 Lindsay, Paul. Resistances to learning EFL. English Language Teaching Journal (London), 31, 3 (1977), 184-90.

Obstacles, or resistances, to learning which arise from attitudes the adult foreign student brings to learning another language, are both conscious and unconscious. Three aspects of these problems are examined: (1) preconceived ideas of learning and teaching, as well as previous learning experience; (2) attitudes to the new culture and effects of the culture on the foreign learner, and (3) the effect of the teacher and of certain teaching techniques on motivation.

78-124 Rivière, Claude. Encore le 'present perfect'. [The present perfect again.] Langues Modernes (Paris), 71, 3 (1977), 231-47.

French-speaking students entering university courses in English display serious problems over the use of the present perfect, including the progressive form, and the relation between this tense and adjuncts of duration and time. No adequate reference seems to exist to clarify these points; this article aims to fill the gap at a level suitable for pedagogical application.

The general system is one of two aspects (perfect; continuous) operating independently of each other and of the non-finite-finite/modal choices. Three time-points are relevant to an utterance: the time of the utterance; the time under reference (situation de base), and the time of the event referred to (temps de procès). Tense (present/past) relates the time under reference to the time of utterance; the perfect aspect relates the time of the event as anterior to (perfect marker) or contemporaneous with (zero) the time under reference. The con- 
tinuous aspect shows whether the action is incomplete (continuous marker) or completed, instantaneous, iterative or a property (zero). [Diagrammatic representations, with commentary and examples.] It can be shown that the operations of adjuncts of duration and time are in accord with the principles established [examples]. A special use of depuis showing the duration of a state subsequent to an instantaneous action (il est arrivé depuis midi) is examined as a translation problem, and a comparison is made of the French and English systems, with a diagram.

78-125 Smith, Larry E. English as an International Auxiliary Language. RELC Journal (Singapore), 7, 2 (1976), 38-42.

The concept of English as an international auxiliary language (EIAL) is proposed as being more useful and realistic than the usual EFL/ESL distinction. English belongs to any country which uses it (either for international communication or internally) and speakers of different varieties can understand each other. The reasons why English should be one of the most frequently used international auxiliary languages are discussed, and it is concluded that a major cause is the number of countries which use it as their principal language, rather than the total number of native speakers, political influence, culture, technological advancement, etc. [Affective, structural anc' rhetorical consequences of a change to EIAL.]

78-126 Stedtfeld, W. Der Gebrauchswert des Englischen für Absolventen und Schüler der Hauptschule. [The value and use of English for leavers and pupils at primary school.] Praxis des Neusprachlichen Unterrichts (Dortmund), 23, 4 (1976), 365-74.

A study carried out in 1975 with the aim of identifying the potential pragmatic goals of language teaching is described. Recent school-leavers now in employment as well as pupils still in the Hauptschule were asked to complete a questionnaire on the use they now make of the English they learned at school. The findings were that knowledge of English was used predominantly in their own country. When used abroad, English was used more frequently in nonEnglish speaking countries than in either England or the USA. The foreign language was used more frequently in private life than in jobs. The use of the four skills took the following order: (1) listening comprehension, mainly used in private life; (2) speaking, usually to English people, or in work situations; (3) reading, usually in leisure time; and (4) writing, usually personal letters to English people. It therefore seems that oral-oriented teaching is not justified and listening comprehension should not be so closely linked with oral proficiency. The chief requirement with regard to reading skills was to extract information. 
78-127 Steltmann, Klaus. Englische Grammatik-Kenntnisse in der gymnasialen Oberstufe. [Knowledge of English grammar in the upper forms of grammar schools.] Praxis des Neusprachlichen Unterrichts (Berlin), 24, 2 (1977), 140-7.

The study lists the most frequent grammatical errors committed by pupils of the two upper forms of grammar schools. It is based on 265 written class exercises on various topics and on several gap-filling tests. A high percentage of mistakes show a lack of basic grammatical knowledge, in particular of morphology. Pupils tend to avoid difficult and typically English constructions which they have not fully mastered. The problem has its roots in the defects and difficulties of teaching the middle forms, e.g. lack of textbook exercises, demanding too extensive a vocabulary, the relatively small number of lessons per week, and special difficulties of this age-group. The general crisis of motivation is aggravated in the teaching of English by the pupil's awareness of his slow progress and despair of being able to master the language. Language teaching in the upper forms will remain a difficult task as long as the teaching of basic grammar in the middle forms is not substantially improved.

FRENCH See also abstracts 78-30, -61, -91, -99/101, -104, -115

78-128 Berwald, Jean-Pierre. Teaching French language skills with commercial television. French Review (Champaign, Ill), 50, 2 (1976), 222-6.

Ways in which commercial television programmes and even short commercials can be used in class at secondary level are outlined. Useful adjuncts are the videotape recorder, including a sound-dubbing device, a single-lens reflex camera and an audio-cassette recorder.

78-129 Ibrahim, Amr. Les professeurs face à la chanson. [Teachers and songs.] Français dans le Monde (Paris), 131 (1977), 33-6 and 45-6.

A group of French and foreign teachers attending a BELC training course asked for sessions on the place of songs in the teaching of French as a foreign language to be included in the programme. The problems involved in choosing and using songs were debated as well as the advantages. The group listened to a number of songs and rejected them as unsuitable before they were able to agree on certain fundamental criteria. A theme was finally chosen, and the song eventually selected was presented to a trial group of students aged between 18 and 30 whose reactions and opinions were studied. [The whole of this issue deals with the use of songs.] 


\section{GERMAN See also abstracts $78-35,-40$}

78-130 Stalb, H. Der Spracherwerb bei Fortgeschrittenen am Beispiel der Stellung von 'nicht'. [Language acquisition in advanced students illustrated by the position of 'nicht'.] Linguistik und Didaktik (Munich), 7, 28 (1976), 282-91.

This article assesses mistakes in the use of nicht in 140 essays by English students in their first and third year of a university course, the second year being spent in Germany, noting the influence of L1 and L2. The interference of the mother tongue is seen to be the reason for the deviation in certain cases, e.g. Die Streiks sind nicht, jedoch/eine Frage ( $/=$ the correct position of nicht); Wir können nicht die Maschine/sehen).

The influence of $\mathrm{L} 1$ is seen to decrease by half as the knowledge of $\mathrm{L} 2$ increases (after a year spent in Germany). It was found that the most difficult points to learn are those similar to the mother tongue; those which are basically different from those of the mother tongue are easier, and the easiest are those items which correspond directly to the mother tongue.

\section{RUSSIAN See also abstracts $78-20,-37,-57,-87,-114$}

78-131 Novikov, L. А. Лингвистика и её значение дяя преподавания русского языка как иностранного. [Linguistics and its significance for the teaching of Russian as a foreign language.] Русский язык за рубежсом (Moscow), 3 (1977), 62-8.

The range of possibilities for interaction between linguistics and languageteaching methods is very great. Of special current importance are the following areas: the systematic nature of language both in its linguistic and methodological interpretation, the semantics of primary linguistic units, the rules underlying the generation of different linguistic units, and the means whereby they are transformed into synonymous expressions, contrastive linguistic description. Current research in each of these areas is briefly surveyed and related to pedagogic considerations with reference to the teaching of Russian [details].

78-132 Rix, David. Russian for sixth-form beginners. Audio-Visual Language Journal (Birmingham), 15, 1 (1977), 96-101.

The York inter-schools sixth-form Russian course was set up to provide an opportunity for pupils to learn Russian, which is not taught in the majority of local schools, and also to find out what levels of proficiency sixth-form beginners can achieve in all four skills on a short course. It was found that shortage of time was not a problem provided that the course was structured and organised 
effectively. The course took place twice a week, after school hours. [Consideration of aims and objectives; use of course books and materials; teaching methods, including an intensive oral introduction.] By the end of the course pupils had achieved good levels of performance in all four skills. Nevertheless, it is to be hoped that Russian will be more widely taught in the earlier years of secondary school. 